\title{
Optimization of Goods Group Order - Process Approach
}

\author{
Pawel Ślaski \\ Institute of Logistics, Department of Mechanical Engineering, Military University of Technology \\ *Corresponding Author: pslaski@wat.edu.pl
}

Copyright (C) 2014 Horizon Research Publishing All rights reserved.

\begin{abstract}
This article proposes an innovative approach to the inventory control process. It presents the possibility of using non-linear programming to optimize the group procurement of goods. Attention was paid to the creation of economies of scale and the occurrence of trade-off relations related to security customer needs while minimizing the fixed and variable costs of logistics. Methodology and tools for practical use, which can be part of the combined strategies of agile and lean supply chain are presented.
\end{abstract}

Keywords Optimization of Goods, Group Order, Process Approach, Logistics

\section{Introduction}

Inventory planning is related to the so-called 'trade-off' relation (meaning 'something for something') that is to such sufficient accumulation supplies in order to protect the customer's needs and their service standards as well as to minimize the costs of procurement and maintenance. Rational management of reserves is not just about the stocks, their size optimization problem is more complex. It also relates to the supply of raw materials in the process of purchasing, maintaining the continuity of supply of work in progress as well as work in progress (called 'in transport'), or the to the supply of goods in the distribution process. A series of classical statistical methods is described in the literature ${ }^{1}$. They enable effective control of inventory at each stage of the supply flow in the supply chain. Mostly they are related to the control of homogenous supply but they are also effective in stochastic and deterministic cases and in them of discontinuity of demand. The most commonly used method for inventory optimizing associated with the procurement of uniform single product is the method of "Economics Order Quantity" (EOQ). EOQ is a characteristic size of the order, at which the total cost of ordering and maintaining inventories are minimal. The method of "EOQ" is associated with the

\footnotetext{
1 1.Krzyżaniak St., Basics of Supplies Managment in Examples, Biblioteka Logistyka, Poznań, 2002.

2. Lysons K., Purchasing and Supply Chain Management, Financial Times Proffesional Ltd 2000.

3.Bozarth C., Handfield R.B., Introduction to Operations and Supply Chain Management, Upper Saddle River, New Jersey, 2006.
}

model R. H. Wilson.

$$
E O Q=\sqrt{\frac{2 \cdot P \cdot c p o}{c m i}}
$$

Where:

$P$ - annual demand,

cpo- the unit cost of the order,

cmi- unit cost of maintaining inventory.

Although EOQ method is widely used in order to optimize the process, its capacity is limited. Mainly due to the fact that it is a deterministic method in which the demand and replenishment cycles are constants in a specified period of time. Further limitations are associated with the lack of deficiency risk in the store and analyzing the size of a single product delivery. Although the applied technologies allow very carefully and quickly to solve the complex optimization problem, the economic size of the supply in each case inventory control, it contemporary trends the inventory management to identify other priorities. In business practice, there is a problem of ordering a variety of selections from one or multiple vendors. It is connected with, co called, the effect of economy scale, which is cutting costs and obtaining discounts with the procurement of raw materials, transport, production and storage of products in large parts.

Let us put forward some questions following research areas:

1. Since the optimal rate of deliveries in EOQ method minimizes the total cost of ordering and maintaining stock of uniform, then what method should be used to reduce these costs by ordering a group of various assortments?

2. What is a decrease in the total cost of ordering and maintenance if the method used to group order of goods compared with the method of EOQ?

3. How does the process approach using empirical method verify the group ordering goods?

Research problems will be solved mainly on the basis of the following methods and research tools:

1. Nonlinear programming,

2. Analysis process,

3. Application SOLVER.

Based on a numerical example is verified using empirical method of group ordering with an analysis of the total cost of ordering and maintaining inventory. 


\section{Assumptions and Methodology Analysis of "The Economic Value of Quantity" (EVQ)}

\section{Assumptions}

In the management of logistics and supply chain there are two strategies, the so-called. agile and lean supply chain, the first one is focused on the customer meeting the highest standards of the service involves:

- a short response time,

- flexibility.

The other one, whose priority is the economy of scale and lower logistics cost is related to:

- small batch production,

- the minimum amount of supplies (A. Harrison, R van Hoek, 2010, p.274).

The methodology developed in the article shows the economic value of the contract "EVQ" that may be a part of the combined strategy (lean and agile) supply chain. EVQ analysis is a method of group ordering a variety of products from a single supplier. Empirical studies confirm that in this case, the main assumption is based on the value of the ordered goods. Economic Value of Quantity results from the economic transformation of Economic Order Quantity (EOQ), which is the result of a deterministic model of order and balances the cumulative annual cost of ordering and maintenance of goods at considered period of time (St. Krzyżaniak, 2002, p 202).

Costs Order (cpo) are divided into:

Fixed ones:

- the cost of the procurement department (salaries (wages), use of facilities, electricity, office supplies). variables:

- costs of the procurement,

- Special costs (such of quality delivery of goods into the warehouse, laboratory tests).

Practically, the unit cost of the contract is calculated as the quotient of the total cost of purchases by the number of orders generated during the year, while the annual cost of the contract, as the product of the number of deliveries per year and the unit cost of the order (1):

$$
\text { асро }=n \cdot \text { сро }
$$

Maintenance costs of inventories fall into the fixed and variable:

Constants are as follows:

- depreciation of storage buildings and their equipment,

- the cost of warehouse personnel.

The variables are as follows:

- capital ones,

- service,

- storage,

- risk.

Practically the unit cost of inventories is calculated from the equation

$$
c m i=c \cdot u_{r}
$$

However, the annual cost of inventory is determined by the formula (3):

$$
a c m i=\frac{Q}{2} \cdot c m i
$$

Where:

$c$ - purchase price of the goods,

$u_{r}$ - ratio of the annual cost of maintaining inventory,

$\frac{Q}{2}-$ the average size of the storage.

Economic Value of Quantity (EVQ) can be described by the equation (4):

$$
\begin{gathered}
E V Q=c \cdot E O Q \\
E V Q=c \cdot \sqrt{\frac{2 \cdot P \cdot c p o}{c m i}} \\
E V Q=\sqrt{\frac{2 \cdot b d \cdot c p o}{u_{r}}}
\end{gathered}
$$

Where:

$E O Q$ - Economic order quantity

$P$ - annual demand

$b d$ - budgeted demand

$c p o$ - the unit cost of the order

$c m i$ - unit cost of inventory maintaining

Other limitations and assumptions are:

$>$ The unit cost of the order is known (cpo),

$>$ There is a known factor of the annual cost of maintaining inventory (if the ratio is different for different products, you must use a weighted average of the ratio).

\section{Methodology}

Methods of analysis "EVQ" comes down to determining the optimal schedule of deliveries at the considered period of time, taking into account the assumptions described and consists of the following steps:

1) the identification of each item of goods value $\left(V_{i}\right)$ demand $(P \cdot C)$ (during the relevant period);

2) calculation of the total value of the goods, $b d=\sum V_{i}$;

3) calculation according to the formula EVQ (5);

4) calculation of the number of deliveries in the group ordering system $l_{d}=\frac{b d}{E V Q}$;

5) calculation $E O Q_{i}=\frac{P_{i}}{l_{d}}$;

6) calculation of the cost of maintaining inventories, such as the annual $a c m i=\sum \frac{E O Q_{i}}{2} \cdot c \cdot u_{r}$;

7) calculation of the cost of the order at the material time асро $=$ cpo $\cdot l_{d}$.

8) calculation of the total cost of inventory $C I=a c p o+$ acmi

In according to the methodology, determined delivery time in schedule to minimize the total cost of inventory in the considered time horizon (St. Krzyżaniak, 2002, p. 204). 


\section{Process Approach to "EVQ" Analysis}

Process approach to this method can be considered being based on SIPOC model (so-called Supliers-Input-Process-Output-Customers) according to the following procedure (Pic.1):

1. You must specify the requirements and expectations of the customer (the customer's requirements are treated as objective pursued by executor process).

2. You need to design a process that will meet these expectations (it is important to include as much as possible the process of increasing its potential usefulness for the customer).

3. Specify the input data to the process (identification of important materials, semi-finished products, information, knowledge, skills, tools, etc. as well as the providers of these top-ups) (P. Grajewski, 2007, p.122).

According to the model SIPOC the purpose of analysed method is to determine the delivery schedule, which would minimize ordering and maintenance costs. Project of the process, that is to say, the transformation zones in the measurable output is based on nonlinear programming. The input data are as follos: the size of requirements at the considered period and the purchase of units of goods.

\section{Implementation of "EVQ" Analysis in Application Solver}

\subsection{Introduction to Nonlinear Programming}

The problem of decision-making such as:

$$
\begin{gathered}
f(x) \rightarrow \max ; f(x) \rightarrow \min \\
g_{i}(X) \geq 0 ; g_{i}(X) \leq 0(\mathrm{i}=1, \ldots, \mathrm{m}) \\
g_{i}(X)=0 ; g_{i}(X)=0(\mathrm{i}=\mathrm{m}+1, \ldots, \mathrm{r})
\end{gathered}
$$

is a task of nonlinear programming if the objective function $\mathrm{f}(\mathrm{x})$ or one of the conditions is non-linear. When analyzing EVQ objective function is non-linear and is associated with related annual costs of inventory (total cost of ordering and maintenance of goods) (6) (E. Ignasiak, Warsaw, 1996, p.154)

$$
\mathrm{f}(\mathrm{x})=\mathrm{cpo} \cdot x+0,5 \cdot u_{r} \cdot \sum_{i=1}^{m} \frac{a_{i} \cdot c_{i}}{x} \rightarrow \min
$$

Where:

$a_{i} ; c_{i}-$ demand and unit price

$x-$ decision variable

$u_{r}$ - ratio of the annual cost of maintaining inventory

The limiting conditions:

$x-$ total

$$
x>0
$$

\subsection{Solution of Nonlinear Task in the Solver Application - A Practical Example}

Warehouse supplies the customers in 10 variety of goods (A.... J) (Pic. 2), which buys from the selected supplier. Size of the annual needs (demands) and the purchase price of the units of the items. The optimization problem is posed as a question:

How to develop an optimal delivery schedule to ensure the minimization of the cost of ordering and maintaining groups of products?

For the optimal solution of the problem, you need a spreadsheet to enter the input parameters:

- demand for goods (number),

- the purchase price of the goods,

- unit cost of delivery order,

- the ratio of the annual cost of maintaining inventory,

- the objective function,

- established, the initial number of supply (Pic. 2).
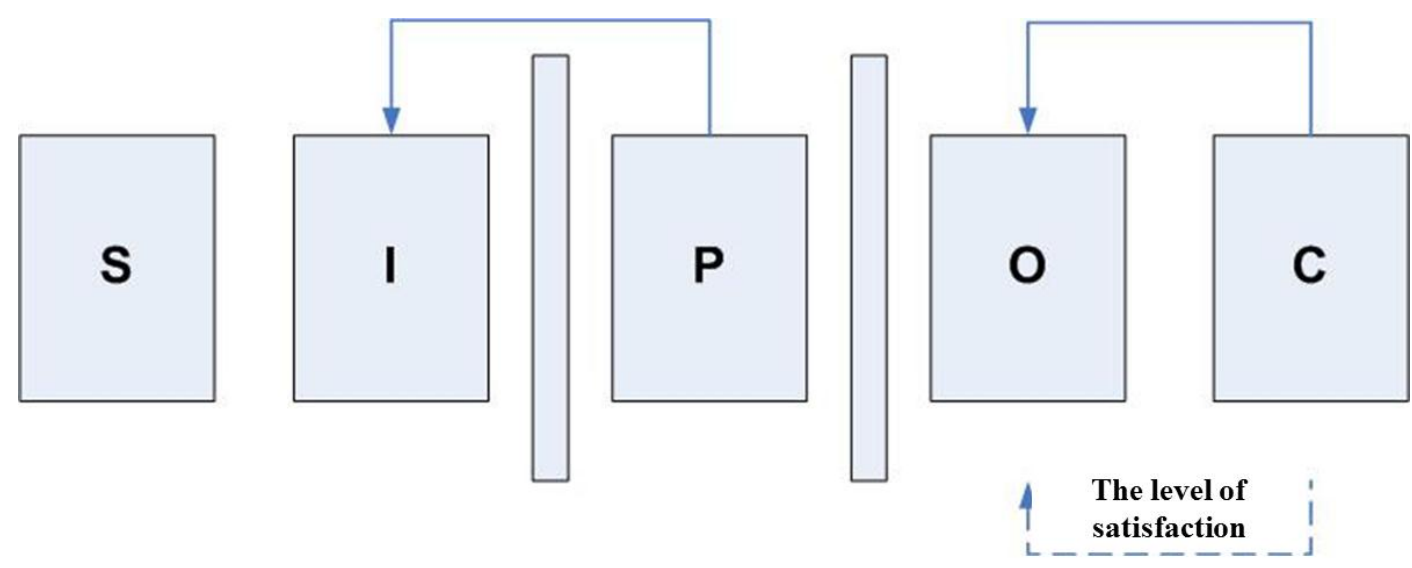


\begin{tabular}{|c|c|c|c|c|c|c|}
\hline Product & Number & Price & Cpo & Ur & $\begin{array}{c}\text { Number of } \\
\text { deliveries }\end{array}$ & $\begin{array}{l}\text { Function of } \\
\text { the purpose }\end{array}$ \\
\hline A & 700 & 6 & 300 & 0,2 & 10 & 13511,5 \\
\hline B & 650 & 10 & & \multirow{4}{*}{\multicolumn{2}{|c|}{ caleulate optimal supplie }} & \\
\hline C & 140 & 300 & & & & \\
\hline D & 1100 & 500 & & & & \\
\hline $\mathbf{E}$ & 300 & 400 & & & & \\
\hline $\mathbf{F}$ & 110 & 15 & & & & \\
\hline G & 400 & 320 & & & & \\
\hline H & 900 & 150 & & & & \\
\hline I & 40 & 1100 & & & & \\
\hline$J$ & 330 & 60 & & & & \\
\hline
\end{tabular}

\section{ANALYSIS EVQ}

Picture 2. Input parameters of "EVQ analysis " Source: Own elaboration

Solving nonlinear optimization problem by using Solver, by using the numerical procedure, called the simplex algorithm. After entering all the data and formulas into a spreadsheet, run Solver (Pic. 3). On the screen, it appears "Solver Parameters" in the dialog box, where in another part of the address field of the objective function, the type of optimization, addresses the decisions variables and the other conditions.

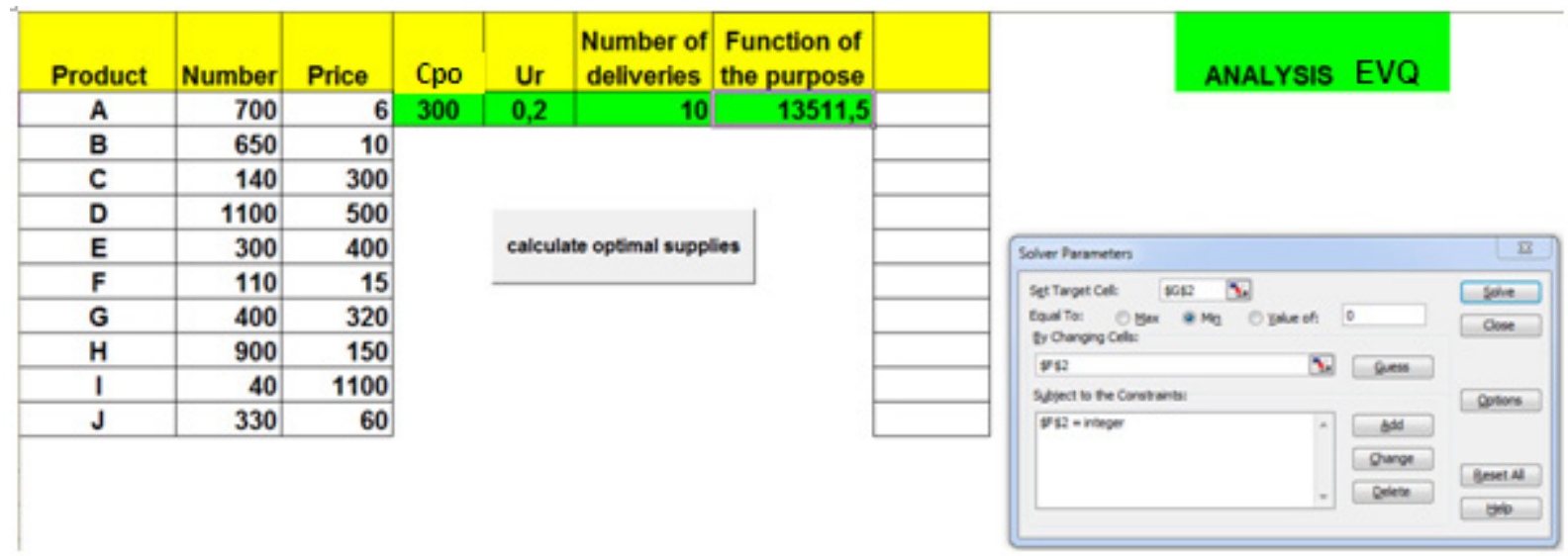

Picture 3. Solver Application dialog nonlinear optimization problem. Source: Own elaboration

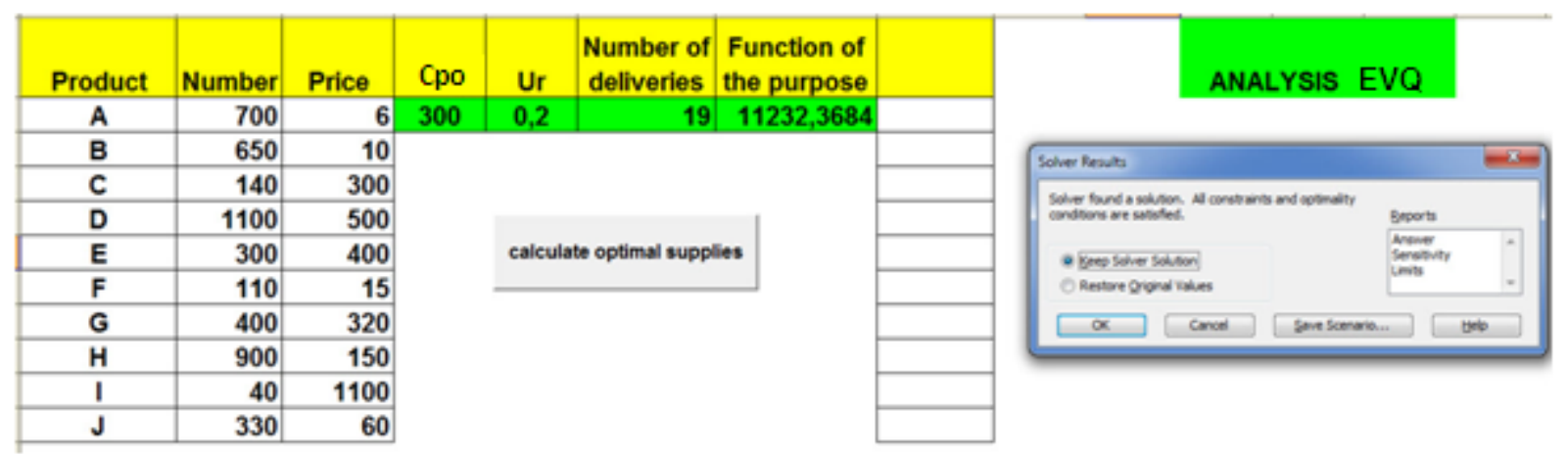

Picture 4. Solver Results. Source: Own elaboration

For so determined the optimum number of supply, it only remains only to determine the economic size of the order of individual selections and what the reader can verify, the verification result (delivery schedule) based on the described in point. 1. Empirical, 8-staged analysis EVQ. Economic sizes of deliveries have been developed in the form of Visual Basic macros for Application (VBA for Application), as the quotients of individual annual of demand (number) by a determined, the optimal number of supplies (Pic.5). 


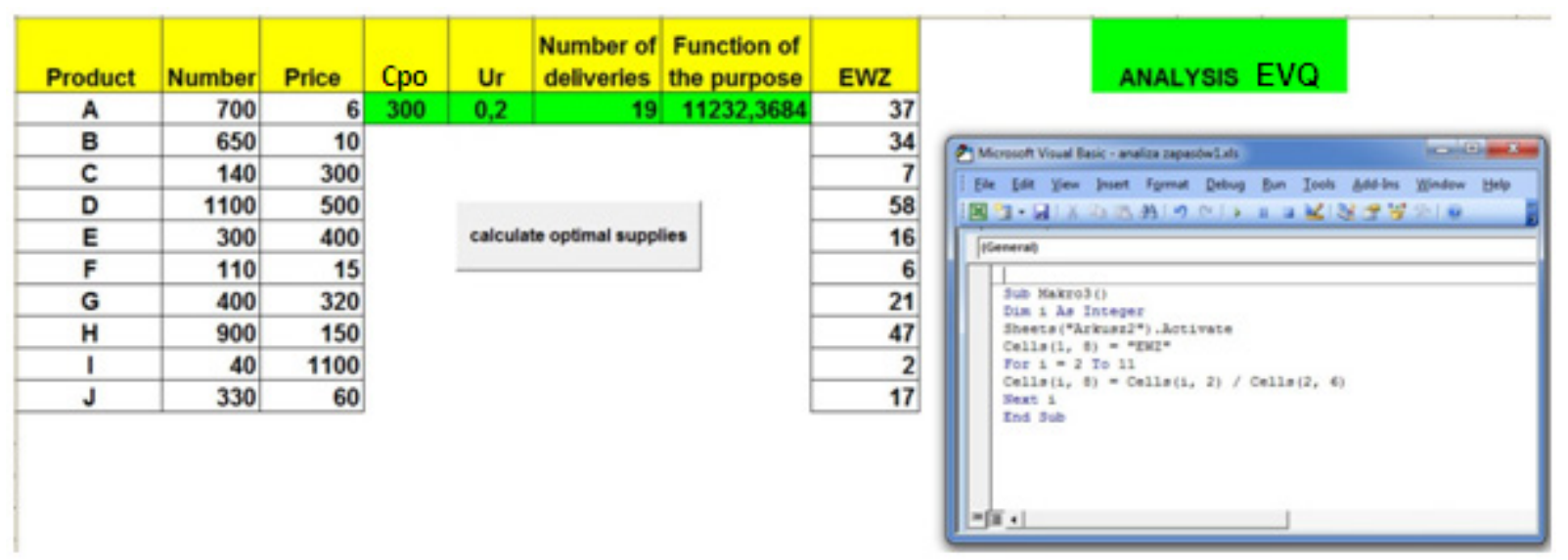

Picture 5. The results. Source: Own elaboration

Final solution of the problem shown in the picture 5 . determines the economic order quantity (EOQ column). Group deliveries of the sizes 19 times (column: number of deliveries) minimizes the objective function (column: function of the aim), which is the total cost of ordering and maintaining inventories $(\$ 11,232.4)$. The reader wants to check that the calculation of the EOQ each product separately and calculate for each size of the total cost of ordering and maintaining inventory, totaling get the total cost amounting to $\$ 27,985$ (costs about $60 \%$ higher than the method of group order). You can also see that the empirical method in accordance with the methodology described in paragraph 1 of this article shall designate the same size as the solution proposed by the author in sections 2 and 3 .

\section{Conclusions}

The Excel spread sheet and Solver application allows to solve complex optimization tasks in economic processes. Due to the ease of use, availability and low cost can be used to support small and medium-sized enterprises. Ability to program spreadsheets, ie creating macros in VBA for Applications, the application becomes flexible and accelerates to take certain decisions. Described group ordering of goods is an example of economies of scale, and although even the simplest computer applications can determine the economic supply of goods treating them individually, it is appropriate, such as non-linear programming solver and applications to order goods group, determines the optimal delivery schedule.

\section{REFERENCES}

[1] Grajewski P., Process Organistion, PWE, Warszawa, 2007.

[2] Ignasiak E, Operation Researches, [w:], PWE, Warszawa, 1996.

[3] Krzyżaniak St., Basics of Supplies Managment in Examples, Biblioteka Logistyka, Poznań, 2002.

[4] Lysons K., Purchasing and Supply Chain Management, Financial Times Proffesional Ltd 2000.

[5] Bozarth C., Handfield R.B., Introduction to Operations and Supply Chain Management, Upper Saddle River, New Jersey, 2006. 